\title{
A MATHEMATICAL MODEL TO COMPUTE RUNOFF VOLUME FROM SMALL WATERSHEDS
}

\author{
Er. A. Sarma ${ }^{1}$ \\ ${ }^{1}$ Ph.D. Scholar, MZLU, Brno, CR (2000)
}

\begin{abstract}
Over the past several years, water resources modelling has become an increasingly important field, from the standpoints of predicting both the quantity and quality of water discharged from watersheds (Ye W. et al.,1997). Models for computation and forecasting floods have been developed in various parts of the world. However, none of the models can be said to be of universal application, because of the fact that local conditions vary (Pfeiffer E. et al., 1997). It is always worth applying a locally developed model for the purpose. To be precise, every flood prone basin must have a local model for the purpose of flood computation and forecasting. This is necessary because floods affect almost all the sectors of development. The present study was therefore, conceived and undertaken to develop a local model for the river Bečva and subsequently to use the same for the river Morava A mathematical model to estimate runoff volume has been developed and will be tested by taking into consideration the hydrological, morphological, soil, vegetative and climatological parameters of the Bečva river basin in the Czech Republic. An attempt will also be made to apply this model within the entire Morava river basin to see as to what extent the model predicted values differ from the measured ones.
\end{abstract}

Keywords: catchment, concentration time, flood forecasting, rainfall-runoff model, watershed

\section{INTRODUCTION}

Over the past several years, water resources modelling has become an increasingly important field, from the standpoints of predicting both the quantity and quality of water discharged from watersheds (Ye W. et al.,1997). Models for computation and forecasting floods have been developed in various parts of the world. However, none of the models can be said to be of universal application, because of the fact that local conditions vary (Pfeiffer E. et al., 1997). It is always worth applying a locally developed model for the purpose. To be precise, every flood prone basin must have a local model for the purpose of flood computation and forecasting. This is necessary because floods affect almost all the sectors of development. The present study was therefore, conceived and undertaken to develop a local model for the river Bečva and subsequently to use the same for the river Morava with the following set of objectives.

- Examination of maximum discharge as a function of climatology, geo-morphology, vegetation

- Derivation of a model to compute flood discharge for a model sub-basin (Bečva)

\section{REVIEW OF LITERATURE}

It is beyond the scope of this paper to enumerate all the literatures, which have been referred to for setting up the model. However, it would be worth mentioning that over two hundred recent literatures on works done in the field of flood computation and forecasting in various parts of the world have been studied by this author. The details of the same will be provided in the final report that is under preparation.

\section{MATERIALS AND METHODS}

There are basically two approaches to developing mathematical models of runoff formation- 1) A basin is considered to be a system whose parameters are unknown and can be determined by means of input and output characteristics and 2) It is assumed that the physical parameters determining runoff formation can be measured directly. On the basis of this assumption a system of differential equations which includes these parameters as partial derivatives is composed. The second approach makes it possible to describe the physical process occurring in the basin in more detail and has therefore been resorted to.

\subsection{Understanding the Process of Runoff Formation}

The process of runoff formation represents a complex interaction of a large umber of parameters both variable and constant, which may be represented as consisting of three principal parts- 1) Water flow on the surface of catchment area 2) Sub-surface flow and Infiltration of water into the soil and evapotranspiration of water. The whole process of runoff depends on a number of factors as detailed below: 


\begin{tabular}{|c|c|c|c|}
\hline Morphometric elements & $\begin{array}{l}\text { Soil and vegetative } \\
\text { condition }\end{array}$ & Climatic condition & \begin{tabular}{|l|} 
Cultural and \\
geographical \\
condition
\end{tabular} \\
\hline $\begin{array}{l}\text { 1. Size and form of basin } 2 \text {. } \\
\text { Length and slope of the stream } \\
\text { 3. Slope of the basin } \\
\text { 4. Width of the basin } \\
\text { 5. Density of the river network }\end{array}$ & $\begin{array}{l}\text { 1. Physical properties of } \\
\text { soil } \\
\text { 2. Absorbing capacity of } \\
\text { soil } \\
\text { 3. Height of ground water } \\
\text { level } \\
\text { 4. Character and area of } \\
\text { vegetative cover }\end{array}$ & $\begin{array}{l}\text { 1. Amount, intensity and } \\
\text { duration of rainfall } \\
\text { 2. Non-uniform distribution of } \\
\text { storm of different intensity and } \\
\text { duration over the area } \\
\text { 3. Non-uniformity of rainstorm } \\
\text { in time } \\
\text { 4. Wind regime ( direction of } \\
\text { cloud movement) }\end{array}$ & $\begin{array}{l}\text { 1. Human } \\
\text { interference } \\
\text { 2. Cultural practices } \\
\text { 3. Other } \\
\text { factors }\end{array}$ \\
\hline
\end{tabular}

\section{Maximum Discharge $\left(Q_{\max }\right)=f$ (Coefficient of runoff, Co-efficient of non-uniformity of rain storm, Co-efficient of shape, Land cover of the catchment, Duration, intensity and amount of precipitation)}

\subsection{General Concept and Genesis of the Model}

The model has been developed from the investigation of the author on storm runoff data, precipitation characteristics, vegetative coverage, soil types, morphometric elements and cultural and geographical conditions (human factors). To develop the model the following basic steps were carried out:

a) Delineation of the catchment with the help of topographic map. However, supplementary information such as municipal drainage maps is also consulted to obtain an accurate depiction of the urban basin's extent

b) Segmentation of the catchment into a number of subcatchments to determine the number and types of stream network components to be used in the model.

c) Each sub-basin is represented by a combination of model components viz. sub-basin runoff, river routing, reservoir, diversion and pump components.

d) The sub-basins and their components are linked together to represent the connectivity of the river basin. This completes the basin schematic.

\section{RESULTS AND DISCUSSION}

The rainfall-runoff model developed is a simplified representation of a complex hydrological system, the system being described by a set of equations together with statements expressing relations between variables and parameters. This paper briefly describes the results obtained in the form of a mathematical model along with its components in the following sections.

\subsection{Model Derivation}

The rainfall-runoff model is an event-based, lumped parameter model for small and medium-sized watersheds and is meant for watersheds, for which a representative synoptic (defined) rainfall can be defined. It is based on the principle of time of travel to the outlet necessitating definition of the design duration of rainstorm. Major application of the model will be in short-time runoff predictions. However, the model could very well be used as a component to the ecological model discussed in Recommendation Part of this author's Ph.D. Thesis.
Various parameters used for development of the model are represented below.

\subsection{Condition for Maximum Runoff}

Maximum runoff occurs when the time of concentration of storm runoff from the catchment to the outlet equals the duration of the rainstorm and can be expressed by-

$$
\begin{array}{ll}
T_{c}=T_{r} & \\
\Rightarrow & T_{r}=\left(\frac{l_{0}}{V_{v}}+\frac{L}{V_{r}}\right)
\end{array}
$$

where,

$\boldsymbol{T}_{\boldsymbol{c}} \quad$ Time of concentration of storm runoff, min

$\boldsymbol{T}_{\boldsymbol{r}} \quad$ Duration of rainstorm, min

$\boldsymbol{V}_{v} \quad$ Velocity of the storm along the valley slopes $\boldsymbol{l}_{\boldsymbol{o}}$, $\mathrm{m} / \mathrm{min}$

$\boldsymbol{V}_{\boldsymbol{r}} \quad$ Velocity of the storm along the river bed $\boldsymbol{L}$, $\mathrm{m} / \mathrm{min}$

$\boldsymbol{l}_{\boldsymbol{o}} \quad$ Length of the valley slope, $\mathrm{m}$

$\boldsymbol{L} \quad$ Length of the river bed, $\mathrm{m}$

The above equation indicates that the flow of the stream consists of the flow along the valley slopes $\boldsymbol{l}_{\boldsymbol{o}}$ and the flow along the riverbed $\boldsymbol{L}$. The first part indicates the movement of the stream over the ground surface in the form of brooks and the second part indicates channel movement of the stream.

\subsection{Stream Velocity}

On the basis of general principles of hydraulics the velocity of the stream along the valley slope can be expressed as-

$$
\boldsymbol{V}_{v}=\boldsymbol{c} \cdot \boldsymbol{h}^{\boldsymbol{n}} \cdot \boldsymbol{J}_{v}^{\boldsymbol{m}} \quad \mathrm{cm} / \mathrm{sec}
$$

Eq. 2 
where,

$\boldsymbol{h} \quad$ Average depth of the stream, mm

$\boldsymbol{J}_{\boldsymbol{v}} \quad$ The average valley slope, $\%=$ $\frac{\left(H_{\text {max }}-H_{\text {min }}\right)}{\sqrt{A}} \quad$ where,

$\boldsymbol{H}_{\max } \quad$ Highest elevation within the watershed, $\mathrm{m}$

$\boldsymbol{H}_{\text {min }} \quad$ Lowest elevation within the watershed, $\mathrm{m}$

$\boldsymbol{A} \quad$ Area of watershed, $\mathrm{m}^{2}$

$\boldsymbol{c}, \boldsymbol{n}$ and $\boldsymbol{m}$ Parameters that depend on the surface characteristics, values of which are obtained at different depths of runoff, type of surface cover and slope. The values of these parameters for valley slope $\boldsymbol{J}_{\boldsymbol{v}} \geq 1 \%$ are presented in the following table.

Experimental values of the surface parameters c, $\boldsymbol{n}$ and $\boldsymbol{m}$ for $J_{v} \geq 1 \%$

\begin{tabular}{|l|l|l|l|l|}
\hline $\begin{array}{l}\text { Cate } \\
\text { gory }\end{array}$ & Surface cover & $\boldsymbol{c}$ & $\boldsymbol{n}$ & $\boldsymbol{m}$ \\
\hline I & Bare surface & 0.73 & 1.0 & 1.0 \\
\hline II & $\begin{array}{l}\text { Intermittent cover with } \\
\text { grass }\end{array}$ & 0.40 & 1.0 & 0.6 \\
\hline III & Sod cover & 0.30 & 1.0 & 0.6 \\
\hline IV & Dense grass & 0.20 & 1.0 & 0.6 \\
\hline V & $\begin{array}{l}\text { Poorly bushed surface, } \\
\text { degraded pasture }\end{array}$ & 0.35 & 1.0 & 0.5 \\
\hline VI & $\begin{array}{l}\text { Good vegetative cover, } \\
\text { young forest growth }\end{array}$ & 0.18 & 1.0 & 0.5 \\
\hline VII & $\begin{array}{l}\text { Dense vegetative cover, } \\
\text { forest of medium age }\end{array}$ & 0.12 & 1.0 & 0.5 \\
\hline VIII & $\begin{array}{l}\text { Well connected, mature } \\
\text { forest with humus in } \\
\text { soil }\end{array}$ & 0.08 & 1.0 & 0.5 \\
\hline
\end{tabular}

\subsection{Hydraulic Behaviour of a Flowing Stream}

The hydraulic behaviour of a stream flowing down a river valley slope is illustrated below taking two adjacent sections $\boldsymbol{X}_{1}$ and $\boldsymbol{X}_{2}$ separated by a distance $\boldsymbol{d} \boldsymbol{x}$.

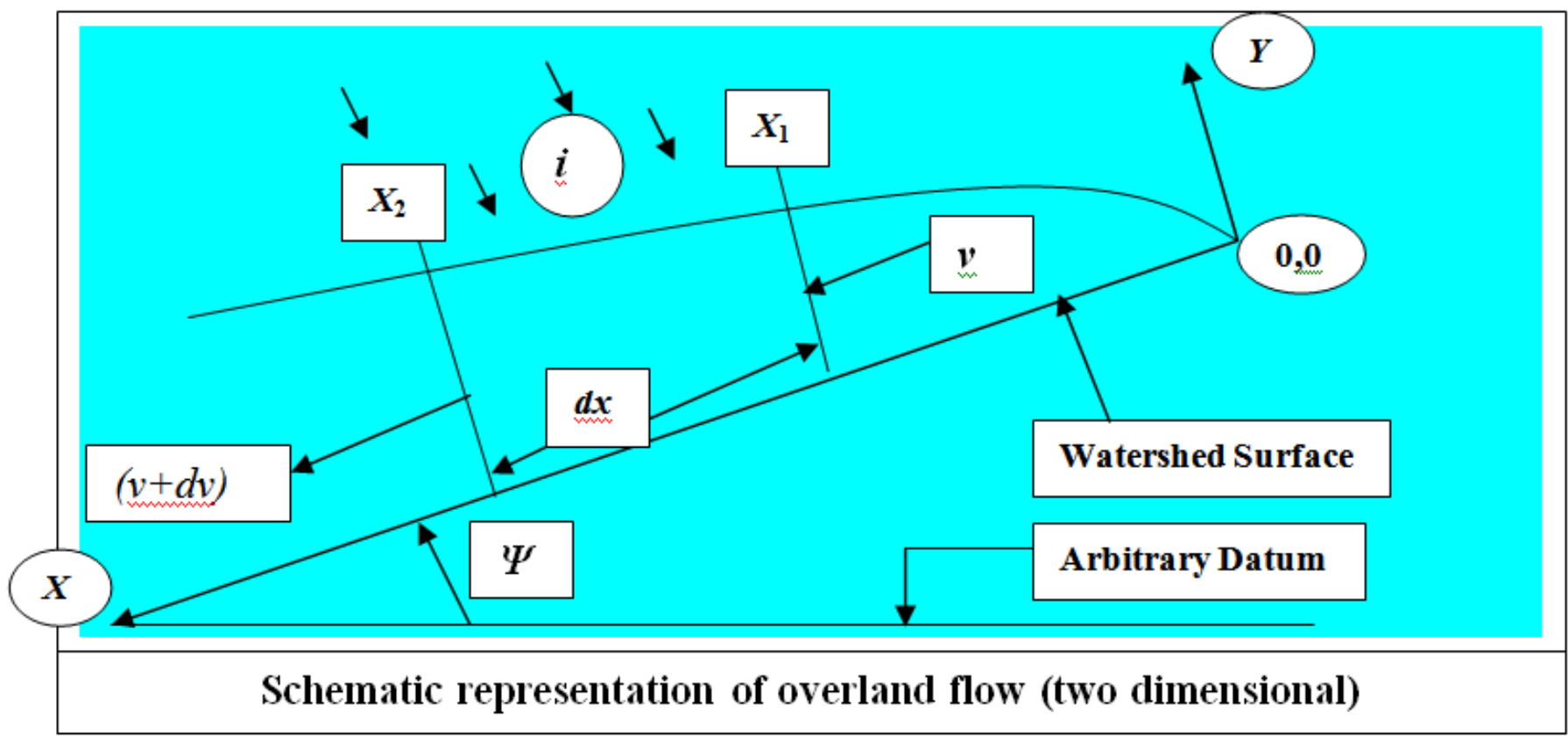

Assuming that this runoff band is being rained with a storm of intensity $\boldsymbol{i}$ and at any time for such a band the conditions of balance and of continuity of mass being satisfied, we can express in accordance with Equation 2 for a band of unit width, the discharge in the section as-

$$
\boldsymbol{q}=\boldsymbol{h} \cdot 1 \cdot \boldsymbol{v}=\boldsymbol{c} \cdot \boldsymbol{h}^{n+1} \boldsymbol{J}_{v}{ }^{m}
$$

Eq. 3

From the conditions of continuity of the stream taking into account the symbols of above Figure and introducing the runoff coefficient $\boldsymbol{C}_{\boldsymbol{r} u}$ to evaluate the percolation losses we obtain:

$$
q_{2}=q_{1}+C_{r u} \cdot i \cdot d x \cdot 1
$$

Eq. 4

where,

$\boldsymbol{q}_{1} \quad$ Unit discharge at section $\boldsymbol{X}_{1}$

$\boldsymbol{q}_{2} \quad$ Unit discharge at section $\boldsymbol{X}_{2}$

Substituting the values of discharge $\boldsymbol{q}$ in Equation 4 we get-

$$
(h+d h)(v+d v)=h \cdot v+C_{r u} \cdot i \cdot d x
$$

Eq. 5 


$$
\begin{array}{cc}
\Rightarrow \quad h \cdot v+h \cdot d v+v \cdot d h+d h \cdot d v=h \cdot v+ \\
C_{r u} \cdot i \cdot d x \quad \text { Eq. } 6
\end{array}
$$

Eq. 7

Now, substituting the values of velocity and its differential from Equation 2 in Equation 7 we get (when $\boldsymbol{n}=1$ ),

$$
\begin{aligned}
& \Rightarrow \quad C_{r u} \cdot i \cdot d x=h \cdot c \cdot J_{v}{ }^{m} d h+h \cdot c \cdot J_{v}{ }^{m} d h \\
& \Rightarrow \quad C_{r u} \cdot i \cdot d x=2 h \cdot c \cdot J_{v}{ }^{m} d h \\
& \Rightarrow \quad C_{r u} \cdot \boldsymbol{i} \cdot \boldsymbol{x}=\boldsymbol{h} \cdot \boldsymbol{c} \cdot \boldsymbol{J}_{v}{ }^{\boldsymbol{m}} \text { Eq. } 9 \text { (Integrating Eq. 8) } \\
& \Rightarrow \quad h=\sqrt{\frac{C_{r u} \cdot i \cdot x}{c \cdot J_{v}^{m}}} \quad \text { Eq. } 10
\end{aligned}
$$

\subsection{Average Storm Velocity along the Valley Slope} $\left(V_{v}\right)$

From the Equation 2 we can write the velocity of flow at a distance $\boldsymbol{x}$ as-

$$
\begin{aligned}
& V_{v}=\boldsymbol{c} \cdot \boldsymbol{h}^{n} \cdot \boldsymbol{J}_{v}{ }^{\mathrm{m}} \\
& \Rightarrow \quad V_{v}=c \cdot J_{v}{ }^{m}\left(\frac{C_{r u} \cdot i \cdot x}{c \cdot J_{v}^{m}}\right)^{n / 2} \\
& \text { the value of } \boldsymbol{h} \text { from Eq. 10) } \\
& \Rightarrow \quad V_{v}=\left(C_{r u} \cdot i \cdot x\right)^{n / 2}\left(c \cdot J_{v}^{m}\right)^{1-n / 2} \\
& \Rightarrow \quad V_{v}=\sqrt{c \cdot J_{v}{ }^{m} \cdot C_{r u} \cdot \boldsymbol{i} \cdot \boldsymbol{x}} \quad \text { (In the limiting }
\end{aligned}
$$$$
\text { case, when } \boldsymbol{n}=\mathbf{1} \text { ) }
$$

Eq. 12

This velocity corresponds to the ultimate moment of runoff. Hence, the average velocity for the period of formation of the stream may be obtained by introducing a suitable multiplying factor $\boldsymbol{f}_{\boldsymbol{m}}$ the value of which mainly depends on the surface cover. Its average value may be assumed as $\mathbf{0 . 7 0}$. Thus, the average velocity for the period of formation of the stream may be expressed as-

$$
V_{v}=f_{m} \sqrt{c \cdot J_{v}^{m} \cdot C_{r u} \cdot i \cdot x}
$$

Eq. 13

\subsection{Velocity of Flow in River Bed $\left(V_{r}\right)$}

The velocity of flow in riverbed $\left(\boldsymbol{V}_{\boldsymbol{r}}\right)$ can be estimated with the help of known hydraulic formulae. However, in many cases data on hydraulic elements for the stream are not available. Under such cases, the situation may be simplified to deal with velocities of one kind only, say $\boldsymbol{V}_{v}$. To achieve this, the length of the riverbed $\boldsymbol{L}$ can be reduced to an equivalent length down the valley slope where the velocity of runoff is $\boldsymbol{V}_{v}$. For that purpose it is necessary to have a correlation for these two kinds of velocities as given below.

$$
\frac{V_{r}}{V_{v}}=S
$$

$$
\Rightarrow \quad V_{r}=S V_{v}
$$

In accordance with the Equation 1, the time of travel to the outlet can be expressed as-

$$
P=\frac{l_{0}}{V_{v}}+\frac{L}{S \cdot V_{v}}=\frac{1}{V_{v}}\left(l_{0}+\frac{L}{S}\right)
$$

And

$$
\boldsymbol{P} \cdot \boldsymbol{V}_{v}=\left(\boldsymbol{l}_{0}+\frac{\boldsymbol{L}}{\boldsymbol{S}}\right)=\boldsymbol{L}_{\pi p}
$$

where,

$\boldsymbol{L}_{\pi p}=$ Calculated length of the way of the river reduced to an equivalent length down the valley slope

From Equation 1 and Equation 16 we get,

$$
L_{\pi p}=\boldsymbol{T} \cdot \boldsymbol{V}_{v}
$$

Substituting the values of $\boldsymbol{V}_{v}$ from Equation 13, when $\boldsymbol{x}=$ $\boldsymbol{l}_{0}$ we get,

$$
\begin{gathered}
L_{\pi p}=0.70 T \sqrt{c \cdot J_{v}{ }^{m} \cdot C_{r u} \cdot i \cdot l_{0}} \\
\text { Eq. 18 } \\
\Rightarrow \quad L_{\pi p}=0.70 T \sqrt{c \cdot J_{v}{ }^{m} \cdot C_{r u} \cdot l_{0}} \sqrt{\frac{H}{T}} \\
\left(i=\frac{H}{T}\right) \\
\Rightarrow \quad L_{\pi p}=0.70 \sqrt{c \cdot J_{v}{ }^{m} \cdot C_{r u} \cdot l_{0}} \sqrt{H \cdot T}
\end{gathered}
$$

Eq. 19 
where,

$\boldsymbol{H} \quad$ Amount of precipitation (mm)

$\boldsymbol{T} \quad$ Duration of precipitation (hr)

\subsection{Relationship between Various Elements of Precipitation}

Considering long-term data of rainstorms on stations located within the Czech Republic in general and the Morava river basin in specific, relationship between various elements of precipitation can be expressed by a general formula as given below. Information regarding monthly rainfall pattern and rainstorms of different intensities within the Morava river basin are provided elsewhere.

Amount of precipitation,

$$
H=K \cdot \Gamma^{x} \cdot T^{y}
$$

Eq. 20

where,

$\boldsymbol{K}$ The climatic coefficient which is subject to wide range of spatial fluctuations in accordance with runoff conditions of the region.
$\Gamma \quad$ Flood return period, year (s)
$\boldsymbol{x} \quad \boldsymbol{0 . 2 7}$ (More or less a stable constant)
$\boldsymbol{y} \quad \mathbf{0 . 3 1}$ (More or less a stable constant)

The values of the climatic constant $\boldsymbol{K}$ for the Morava river basin are presented in the form of isolines.

Now from Eq. 19 we have,

$$
\sqrt{\boldsymbol{H} \cdot \boldsymbol{T}}=\frac{\boldsymbol{L}_{\pi p}}{0.7 \sqrt{\mathrm{c} \cdot \boldsymbol{J}_{v}{ }^{m} \cdot \boldsymbol{C}_{r u} \cdot \boldsymbol{l}_{0}}}
$$

And from Eq. 20 we have,

$$
\sqrt{H \cdot T}=\sqrt{K \cdot \Gamma^{x} \cdot T^{1+y}}
$$

Equating Eq. 21 and Eq. 22 we can write,

$$
\begin{array}{cc}
\sqrt{K \cdot \Gamma^{x} \cdot T^{1+y}}=\frac{L_{\pi p}}{0.7 \sqrt{c \cdot J_{v}{ }^{m} \cdot C_{r u} \cdot l_{0}}} \\
\Rightarrow \quad K \cdot \Gamma^{x} \cdot T^{1+y}=\left[\frac{L_{\pi p}}{0.7 \sqrt{c \cdot J_{v}^{m} \cdot C_{r u} \cdot l_{0}}}\right]^{2} \\
\Rightarrow \quad T=\left[\frac{L_{\pi p}}{0.7 \sqrt{K \cdot \Gamma^{x} \cdot c \cdot J_{v}{ }^{m} \cdot C_{r u} \cdot l_{0}}}\right]^{\frac{2}{1+y}}
\end{array}
$$

Eq. 23

\subsection{Coefficient of Roughness $\left(C_{r o}\right)$}

The coefficient of roughness $\boldsymbol{C}_{\boldsymbol{r} \boldsymbol{}}$ characterises the type of cover of the catchment area and its value changes from surface to surface. The value of $\boldsymbol{C}_{\text {ro }}$ can be found out from the following expression,

$$
C_{r o}=0.7 \sqrt{0.01 \cdot 60 \cdot c}
$$

Or

$$
C_{r o}=\left(\xi \times C_{f}\right)
$$

where,

$$
\begin{array}{ll}
\boldsymbol{\xi} & \text { Soil coefficient } \\
\boldsymbol{C}_{\boldsymbol{f}} & \text { Coefficient of forest cover }
\end{array}
$$

For the purpose of the present study, the expression Eq. 23b has been used.

\section{Values of the roughness coefficient $C_{r o}$}

\begin{tabular}{|l|l|l|l|}
\hline Category & Surface cover & $\boldsymbol{c}$ & $\boldsymbol{C}_{\boldsymbol{r o}}$ \\
\hline I & Dense grass & 0.20 & 0.24 \\
\hline II & Bare surface & 0.73 & 0.46 \\
\hline III & $\begin{array}{l}\text { Intermittent } \\
\text { surfaces }\end{array}$ & 0.40 & 0.34 \\
\hline IV & Dense forest & 0.10 & 0.17 \\
\hline V & Moderate forest & 0.15 & 0.21 \\
\hline
\end{tabular}

\subsection{Coefficient of Non-Uniformity of Rainstorm, $\beta$}

Examination of rainstorm data for the last 25 years reveals the following facts-

- As the distance from the centre of the storm increases, the intensity of the storm correspondingly decreases.

- With increasing duration of rainstorm with the same intensity, its non-uniformity is smoothed out meaning transition to continuous rain.

- Increasing intensity of the rainstorm results in increased non-uniformity.

These factors in nature are interconnected in combination and hence can be represented geometrically as a family of curves as given below:

$$
\begin{gathered}
\boldsymbol{\beta}=\boldsymbol{e}^{-0.28 \cdot \boldsymbol{A}^{0.5}} \sqrt[3]{\boldsymbol{i}} \boldsymbol{T}^{-0.3} \\
\text { the present study) } \\
\boldsymbol{\beta}=\boldsymbol{e}^{-0.20 \cdot \boldsymbol{A}^{0.6}} \sqrt[3]{\boldsymbol{i}} \boldsymbol{T}^{-0.25}
\end{gathered}
$$


where,

$\boldsymbol{\beta}=$ Coefficient of non-uniformity of the rainstorm

$\boldsymbol{A}=$ Area of the basin, $\mathrm{km}^{2}$

$\boldsymbol{i}=$ Intensity of rainstorm, $\mathrm{mm} / \mathrm{min}$

$\boldsymbol{T}=$ Duration of rainstorm, $\min$

\subsection{Coefficient of Shape $\left(C_{s}\right)$}

Analysis of rainstorm data reveals that the intensity of a rainstorm varies with time and space indicating that the shape of a watershed can have a significant effect on the maximum discharge. This can be taken into account by introducing a coefficient of the shape $\boldsymbol{C}_{s}$ of the catchment area or a coefficient of non-uniformity of the rainstorm in time. In practice, the values of $\boldsymbol{C}_{s}$ are determined in accordance with the ratio $\left(\frac{\boldsymbol{W}_{\boldsymbol{m}}}{\boldsymbol{W}}\right)$, where,

$\boldsymbol{W}_{\boldsymbol{m}} \quad$ Maximum width of the catchment area, $\mathrm{km}$

$\boldsymbol{W} \quad$ Mean width of the catchment area, $\mathrm{km}$
The relationship between $\boldsymbol{C}_{s}, \boldsymbol{W}_{\boldsymbol{m}}$ and $\boldsymbol{W}$ may be expressed as given below:

$$
C_{s}=0.25\left(\frac{W_{m}}{W}\right)+0.75
$$

\subsection{Coefficient of Runoff $\left(C_{r u}\right)$}

The coefficient of runoff $\boldsymbol{C}_{\boldsymbol{r} \boldsymbol{u}}$ can be determined by the formula given below.

$$
C_{r u}=\xi(i+0.1)^{0.345} \cdot \boldsymbol{T}^{0.15}
$$

Where,

$\boldsymbol{i}$ Intensity of rainstorm, $\mathrm{mm} / \mathrm{min}$

$\boldsymbol{T} \quad$ Duration of rainstorm, $\min$

$\boldsymbol{\xi} \quad$ Soil coefficient values determined by experimental study of the runoff coefficient at special stations and by experimental work on sample plots are given in the table below.

Values of the Soil Coefficient $\xi$

\begin{tabular}{|l|l|l|}
\hline Category & Characteristics of soil conditions of the basin & Value of $\boldsymbol{\xi}$ \\
\hline I & Soil with gravel and stone (gravel>50\%) & 0.04 \\
\hline II & Soil with Gravel (Gravel $=10-50 \%)$ & 0.06 \\
\hline III & Loose rock (sandy soil) & 0.08 \\
\hline IV & Permeable soils (loamy sand and sandy loam soil) & 0.22 \\
\hline V & Chestnut soils (Chernozem) & 0.27 \\
\hline VI & Clayey loam & 0.32 \\
\hline VII & Hardly permeable soils (heavy loam, clay soil) & 0.40 \\
\hline
\end{tabular}

Values of the coefficient of runoff $\left(C_{r u}\right)$

\begin{tabular}{|l|l|l|l|}
\hline $\begin{array}{l}\text { Flood Frequency, } \boldsymbol{\Gamma} \\
\text { (year) }\end{array}$ & Climatic Constant, $\boldsymbol{K}$ & $\begin{array}{l}\boldsymbol{C}_{r u} \\
\boldsymbol{A} \leq \mathbf{2 0} \mathbf{~ k m}^{\mathbf{2}}\end{array}$ & $\begin{array}{l}\boldsymbol{C}_{\boldsymbol{r u}} \\
\boldsymbol{A}>\mathbf{2 0} \mathbf{~ k m}^{\mathbf{2}}\end{array}$ \\
\hline 100 & 5 & 0.60 & 0.55 \\
\hline 100 & 8 & 0.70 & 0.65 \\
\hline 20 & 5 & 0.55 & 0.50 \\
\hline 20 & 8 & 0.60 & 0.55 \\
\hline 2 & 5 & 0.45 & 0.43 \\
\hline 2 & 8 & 0.50 & 0.48 \\
\hline
\end{tabular}

- For soils of Category III the value of $\boldsymbol{C}_{\boldsymbol{r} u}$ must be decreased by about 5-8\%.

- For soils of Category $\mathrm{V}$ the value of $\boldsymbol{C}_{\boldsymbol{r} \boldsymbol{u}}$ must be increased by about $5-10 \%$

\subsection{Coefficient of Forest Cover $\left(C_{f}\right)$}

This coefficient takes into account the forest cover in the basin and is introduced in the formula of the runoff coefficient and can be expressed as given below.

$$
\boldsymbol{C}_{f}=\frac{1}{1+0.2\left(\frac{\boldsymbol{A}_{f}}{\boldsymbol{A}}\right)}
$$

where,

$\boldsymbol{A}_{\boldsymbol{f}} \quad$ Area covered by forest, $\mathrm{km}^{2}$ and 


\subsection{Length of the Valley Slope $\left(l_{0}\right)$}

The length of valley slope can be found out from the following relationship.

$$
l_{0}=\frac{1000 \cdot A}{2\left(L+\sum l\right)}
$$

where,

$$
\begin{array}{ll}
\boldsymbol{A} & \text { Area of the basin, } \mathrm{km}^{2} \\
\boldsymbol{L} & \text { Length of the main river bed, } \mathrm{km} \\
\boldsymbol{\Sigma} \boldsymbol{l} & \text { Total length of streams, km }
\end{array}
$$

In case of unavailability of data on total length of main streams it is possible to calculate the length of valley slope from the relation given below.

$$
\boldsymbol{l}_{0}=\frac{1000 \cdot \boldsymbol{A}}{4 \cdot \boldsymbol{L}}
$$

\subsection{Final Form of the Model}

Based on the above mentioned elements, derivations, discussion and analysis the final computational model for the maximum rainstorm discharge can be presented as follows:

$$
Q_{\max }=16.67 C_{r u} \cdot \beta \cdot C_{s} \cdot A\left(\frac{H}{T}\right)
$$

where,

$\boldsymbol{C}_{\boldsymbol{r u}}$ Coefficient of runoff that is determined from nomogram or from the formula

$$
=\left(\xi \times C_{f}\right) \xi \times(i+0.1)^{0.345} \cdot \boldsymbol{T}^{0.15}
$$

$\begin{array}{ll}\boldsymbol{i} & \text { Intensity of rainstorm, } \mathrm{mm} / \mathrm{min} \\ \boldsymbol{\xi} & \text { Soil coefficient } \\ \boldsymbol{\beta} & \text { Coefficient of non-uniformity of the rainstorm } \\ \boldsymbol{A} & \text { Area of the basin, } \mathrm{km}^{2} \\ \boldsymbol{C}_{\boldsymbol{s}} & \text { Coefficient of shape of watershed } \\ \boldsymbol{H} & \text { Total amount of precipitation, } \mathrm{mm} \\ \boldsymbol{T} & \text { Total duration of rainstorm, min }\end{array}$

\subsection{Validation of Maximum Discharge}

Validity of maximum discharge obtained by the Equation 31 is checked up by the ratio of velocities of flow in the river bed and on the valley slope. The methodology for the purpose is explained below. As a guide to overall check, use of the Eq. 1 is also explained with respective examples.

\section{Velocity in the River Bed $\left(V_{r}\right)$}

The velocity in the river bed, which is averaged for the time of the formation of the maximum discharge, can be determined by the following empirical formula for rivers with a bed consisting of light boulders.

$$
\boldsymbol{V}_{\boldsymbol{r}}=0.75 \cdot\left[\boldsymbol{Q}_{\max }{ }^{0.2} \cdot \boldsymbol{J}_{r}^{\left(0.24+1.6 J_{r}\right)}\right]
$$

where,

$$
\begin{array}{ll}
\boldsymbol{V}_{\boldsymbol{r}} & \text { Velocity in the river bed, } \mathrm{m} / \mathrm{sec} \\
\boldsymbol{Q}_{\max } & \text { Maximum rainstorm discharge, } \mathrm{m}^{3} / \mathrm{sec} \\
\boldsymbol{J}_{\boldsymbol{r}} & \text { Average slope of the river bed, } \%
\end{array}
$$

\section{Velocity Down the Valley Slope $\left(V_{v}\right)$}

The velocity down the valley slope is given by,

$$
V_{v}=C_{r o} \sqrt{J_{v}{ }^{m} \cdot C_{r u} \cdot i \cdot l_{0}}
$$

where,

$$
\begin{array}{ll}
\boldsymbol{C}_{\boldsymbol{r}} & \text { Coefficient of roughness } \\
\boldsymbol{J}_{v} & \text { Average valley slope, } \% \\
\boldsymbol{C}_{r u} & \text { Coefficient of runoff } \\
\boldsymbol{i} & \text { Intensity of rainfall, } \mathrm{mm} / \mathrm{min} \\
\boldsymbol{l}_{0} & \text { Length of valley slopes, } \mathrm{m}
\end{array}
$$

\section{Ratio of velocity $S$}

The ratio of velocity is given by the factor $\left(S=\frac{V_{r}}{V_{v}}\right)$. If this ratio exceeds that originally chosen by $10 \%$ or more, a re-computation must be done. For initial assumption and to start with the process of computation, the following graph has been provided. The graph has been drawn for different values of velocity ratios $\left(S=\frac{V_{r}}{V_{v}}\right)$ and the length factor $\left(\boldsymbol{L} / \boldsymbol{l}_{\boldsymbol{0}}\right)$. For other values, correction factors are given in the following Figure. 

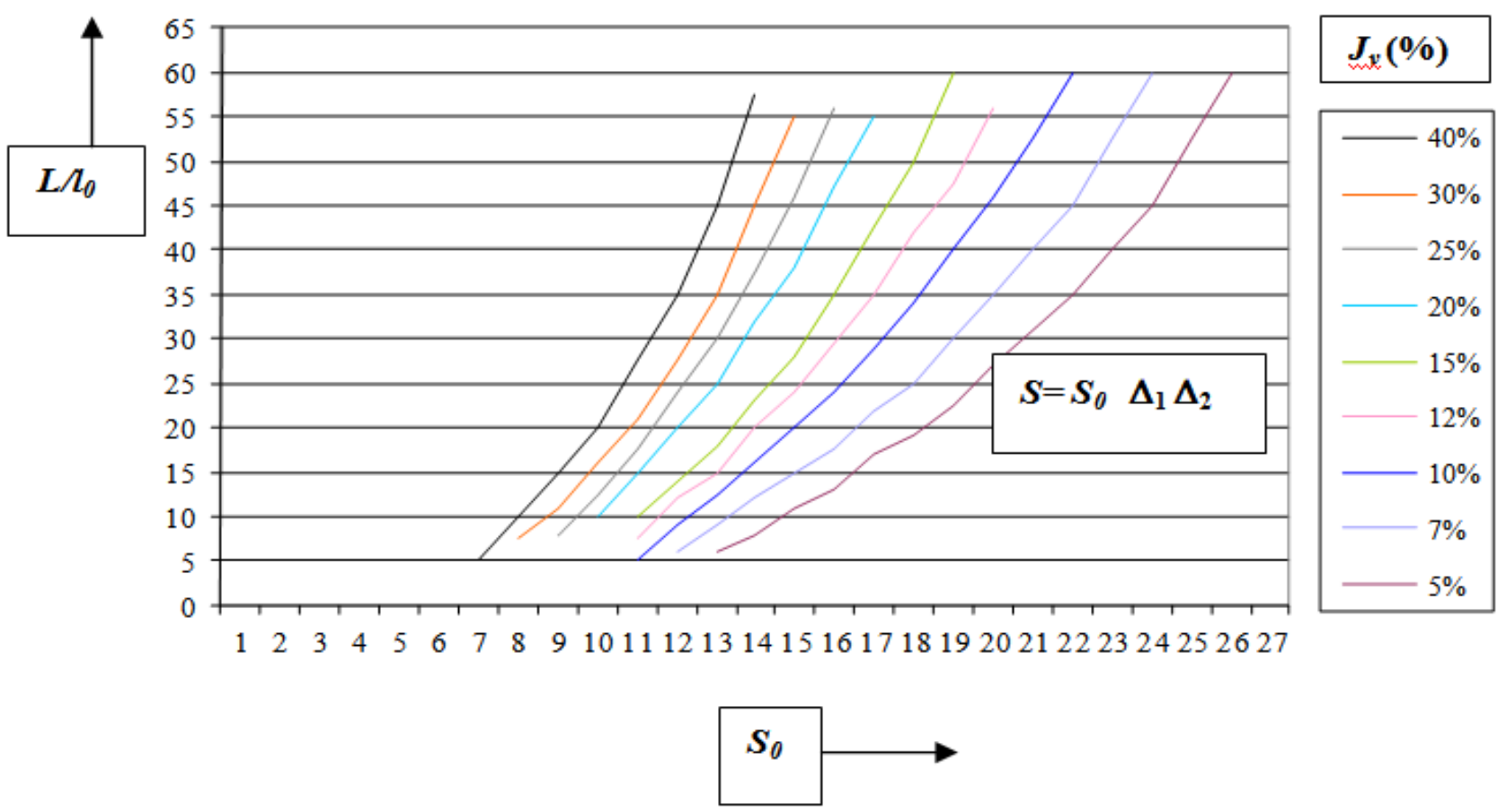

\section{Correction to $S_{0}$ when $K \neq S$}

\begin{tabular}{|l|l|l|l|l|l|l|l|l|l|l|}
\hline $\boldsymbol{K}$ & 2.00 & 3.00 & 4.00 & 4.50 & 5.00 & 5.50 & 6.00 & 7.00 & 8.00 & 9.00 \\
\hline$\Delta_{\mathbf{1}}$ & 1.25 & 1.17 & 1.09 & 1.05 & 1.00 & 0.96 & 0.92 & 0.85 & 0.77 & 0.69 \\
\hline
\end{tabular}

\section{Correction to $S_{0}$ when $\Gamma \neq 100$}

\begin{tabular}{|l|l|l|l|l|l|l|l|l|l|}
\hline$\Gamma$ & 1000 & 100 & 50 & 30 & 25 & 20 & 10 & 5 & 2 \\
\hline$\Delta_{\mathbf{2}}$ & 0.73 & 1.0 & 1.10 & 1.17 & 1.20 & 1.23 & 1.36 & 1.50 & 1.71 \\
\hline
\end{tabular}

\section{Graph for preliminary assessment of the value of $S$}

\section{Guideline}

The above Figure can be used as a guide for preliminary calculations of the ratio of velocity $\boldsymbol{S}$, which shows $\boldsymbol{S}$ as a function of $\left(\frac{\boldsymbol{L}}{\boldsymbol{l}_{0}}\right)$ and watershed/valley slope $\boldsymbol{J}_{\boldsymbol{v}}$. The graph is made for $\boldsymbol{K}=5$ and $\Gamma=100$ years. For other values of $\boldsymbol{K}$ and $\boldsymbol{\Gamma}$ corrections in the form of multipliers $\Delta_{1}$ and $\Delta_{2}$ are introduced as shown in the table below the above figure

\section{CONCLUSION}

The model developed for the purpose of flood computation can be used in the Bečva watershed. The specific results in this study will not be rigorously tested because of a lack of sufficiently detailed spatially explicit ground observational data in the Morava region. Because the model currently lacks a rainfall forecasting and estimation function, it can only be applied to storm event simulations with the help of rainfall input data received from weather stations. The finding justifies the findings of Romanowicz, R. et al.1998 and Goppert, $\mathrm{H}$ et al. 1998. However, the author plans to add rainfall budget functions to the model in the near future. The accuracy of model could be improved by running the model for an extended period of time with true climate data as input. The study would be able to play a complementary role in areas like, project planning for irrigated areas, reclamation works, water requirements for basins, interstate and other litigation, international negotiations and other water related charges and norms.

\section{ACKNOWLEDGEMENT}

The author expresses deep sense of gratitude his research advisor and guide Doc. Ing. Václav Tlapák, CSc, Head, Department of Forest Engineering and Reclamation, Mendel University of Agriculture and Forestry, Brno for his wise counseling, valuable suggestions, keen interest, generous support, constructive criticism and constant encouragement throughout the course of the investigation. 


\section{REFERENCES}

[1] Ye, W., Bates, B. C., Viney, N. R., Sivapalan, M. and Jakeman, A. J. (1997). Performance of conceptual rainfall-runoff models in low-yielding ephemeral catchments. Water Resources Research, Vol. 33(1), pp. 153-166.

[2] Pfeiffer, E., Simon, M., Sieker, F. and Verworn, H. R. (1997). Optimisation of the rehabilitation of the Emscher drainage system using continuous rainfallrunoff modeling. Water Science and Technology. Vol. 36(8-9), pp. 33-37.

[3] Romanowicz, R. and Beven, K. (1998). Dynamic real-time prediction of flood inundation probabilities. Hydrological Sciences Journal. Vol. 43(2), pp. 181196.

[4] Goppert, H., Ihringer, J. and Plate, E. J. (1998). Flood forecast model for improved reservoir management in the Lenne River catchment, Germany. Hydrological Sciences Journal. Vol. 43(2), pp. 215-242. 